\title{
The contribution of inspiratory muscles function to exercise limitation in heart failure: pathophysiological mechanisms
}

\section{Contribuição da musculatura inspiratória na limitação ao exercício na insuficiência cardíaca: mecanismos fisiopatológicos}

Jorge P. Ribeiro',2, Gaspar R. Chiappa', Carine C. Callegaro',3

\begin{abstract}
Background: Heart failure induces histological, metabolic and functional adaptations in the inspiratory muscles. This inspiratory muscle weakness, which occurs in $30 \%$ to $50 \%$ of the heart failure patients, is associated with reduction in the functional capacity, reduction in the quality of life and with a poor prognosis in these individuals. Objectives: The objective of this review was to discuss the pathophysiological mechanisms that may explain the role of the inspiratory muscles in the exercise limitation with focus in the reflexes that control the ventilation and the circulation during the exercise. Method: We performed searches in the PUBMED database using the terms "inspiratory muscles", "inspiratory muscle training", "metaboreflex" and chemoreflex" and including studies published since 1980. Results: Inspiratory muscle weakness is associated with exercise intolerance and with an exaggerated inspiratory chemoreflex and metaboreflex in heart failure. The inspiratory metaboreflex may be attenuated by the inspiratory muscle training or by the aerobic exercise training improving the exercise performance. Conclusions: Patients with heart failure may present changes in the inspiratory muscle function associated with inspiratory chemoreflex and metaboreflex hyperactivity, which exacerbate the exercise intolerance.
\end{abstract}

Keywords: inspiratory muscle training; rehabilitation; chemoreflex; metaboreflex; heart failure.

\section{Resumo}

Contextualização: A insuficiência cardíaca (IC) acarreta alterações histológicas, metabólicas e funcionais dos músculos inspiratórios. A fraqueza dos músculos inspiratórios, que ocorre em $30 \%$ a $50 \%$ dos pacientes com IC, associa-se com a redução da capacidade funcional, prejuízos para a qualidade de vida e piora no prognóstico desses indivíduos. Objetivos: Discutir os mecanismos fisiopatológicos que potencialmente explicam o papel da musculatura inspiratória na limitação ao exercício, abordando-se os reflexos que controlam a ventilação e a circulação durante o exercício. Método: Foram realizadas pesquisas na base de dados PUBMED, utilizando os termos inspiratory muscles, inspiratory muscle training, metaborreflex e chemoreflex e incluindo estudos publicados desde 1980. Resultados: A fraqueza muscular inspiratória está relacionada com intolerância ao exercício e com exacerbação do quimiorreflexo e do metaborreflexo inspiratório na IC. O metaborreflexo inspiratório pode ser atenuado pelo treinamento muscular inspiratório ou pelo treinamento aeróbico, melhorando o desempenho ao exercício. Conclusões: Os pacientes com IC podem apresentar alterações da função muscular inspiratória associadas com hiperatividade quimiorreflexa e metaborreflexa inspiratória, as quais podem agravar a intolerância ao exercício.

Palavras-chave: treinamento inspiratório; reabilitação; quimiorreflexo; metaborreflexo; insuficiência cardíaca.

Received: 07/28/2011 - Revised: 01/24/2012 - Accepted: 03/28/2012

\footnotetext{
'Laboratory of Exercise Physiopathology, Department of Cardiology, Hospital de Clínicas, Porto Alegre, RS, Brazil

${ }^{2}$ Department of Medicine, School of Medicine, Universidade Federal do Rio Grande do Sul (UFRGS), Porto Alegre, RS, Brazil

${ }^{3}$ Laboratory of Physiology, Universidade de Cruz Alta (UNICRUZ), Cruz Alta, RS, Brazil

Correspondence to: Carine Cristina Callegaro, Laboratório de Fisiologia, Universidade de Cruz Alta, Campus Universitário Dr. Ulisses Guimarães, Rodovia Municipal Jacob Della Mea, Km 5,6,

Parada Benito, CEP 98.020-290, Cruz Alta, RS, Brasil, e-mail: ccallegaro84@gmail.com
} 


\section{Introduction $: \because$.}

It has been proposed for several years that impairments in the peripheral skeletal muscle function contribute to the pathophysiology of heart failure (HF). During this period, it has been shown that skeletal muscle abnormalities limit the aerobic capacity during the exercise, which results in metabolites accumulation in the muscles leading to sensitize muscle receptors called metaboreceptors. The metaboreceptors activation induces a reflex response, which results in hyperventilation exacerbating the dyspnea sensation. Moreover, it promoves peripheral vasoconstriction with reduction of blood flow which contributes for the reduction of the tolerance to the exercise on $\mathrm{HF}^{1}$.

More recently ${ }^{2-7}$, studies have shown that inspiratory muscles can also limit physical performance to exercise in healthy subjects ${ }^{8,9}$ and also in athletes ${ }^{10-13}$. Similarly, changes in the inspiratory muscles play an important role in the pathophysiology of exercise limitation in HF. One of these changes is the inspiratory muscle weakness, arbitrarily defined as a maximal inspiratory pressure $\left(\mathrm{PI}_{\max }\right)$ less than $70 \%$ of the predicted for age and $\operatorname{sex}^{14-16}$. Patient with inspiratory muscle weakness may have a reduced functional capacity determined by the peak oxygen consumption $\left(\mathrm{VO}_{2 \text { peak }}\right)^{17}$. In addition, inspiratory muscle strength and resistance are directly associated to $\mathrm{V}_{2 \text { peak }}$ in patients with recent acute myocardial infaction ${ }^{18}$, reinforcing the idea that the inspiratory muscles may contribute for the reduction of functional capacity. A recent study shows that inspiratory muscle strength is also associated with the central hemodynamic measurements at rest, including cardiac output, mean arterial pulmonary pressure and pulmonary vascular resistance in patients with $\mathrm{HF}^{19}$. However, no correlation between inspiratory muscle strength and left ventricular ejection fraction was found ${ }^{20}$. Finally, inspiratory muscle strength, assessed by $\mathrm{PI}_{\max }$, has an independent impact on the prognosis of patients with $\mathrm{HF}^{20,21}$.

Functional changes of inspiratory muscles may contribute to the activation of cardiovascular reflexes, which aggravate the exercise limitation in HF. Among these reflexes, we highlight the exacerbation of metaboreflex induced by the work of the inspiratory muscles ${ }^{8,9,15}$ and the increase of the ventilatory responses mediated by the chemorefle $\mathrm{x}^{22-24}$ during the exercise. In the present review, we will discuss the role of the inspiratory chemoreflex and metaboreflex in the exercise limitation in HF.

\section{Chemoreflex:::}

The appropriate tissue oxygen supply is maintained by adjustments of the circulation and the ventilation mediated by the complex interaction of multiple systems, with emphasis on the arterial baroreflex, central and peripheral chemoreflex, ergoreflex and pulmonary stretch re$\mathrm{flex}^{22}$. Chemoreflexes are the main mechanisms of control and management of the ventilatory responses to changes in the arterial oxygen and carbon dioxide concentrations ${ }^{25}$. The central chemoreceptors, located on the ventral surface of medulla (bulb), respond primarily to the variations of partial pressure of $\mathrm{CO}_{2}\left(\mathrm{PCO}_{2}\right)$ in the arterial blood. The peripheral chemoreceptors, located in the common carotid artery and in the aorta artery with afferent input to the respiratory center located at the bulb and at the nucleus of the solitary tract, respond primarily to the variations of partial pressure of $\mathrm{O}_{2}\left(\mathrm{PO}_{2}\right)$ in the arterial blood ${ }^{22}$. Thus, both variations in $\mathrm{PO}_{2}$ and $\mathrm{PCO}_{2}$ result in changes in pulmonary ventilation. In addition, the activation of the central and peripheral chemoreflexes increases the sympathetic nervous activity, which results in the increase of heart rate and blood pressure ${ }^{22,26-28}$. In contrast, the increase of the ventilation sensitizes pulmonary stretch receptors located in the bronchi, bronchioles, and lungs, which detect excessive stretching of the lungs, sending information to the dorsal group of respiratory neurons resulting in negative feedback, preventing therefore additional gains of inspiratory volume ${ }^{29}$. Similarly, the increase in blood pressure induced by the chemoreflex can be counterbalanced by the activation of the arterial baroreflex. The elevation of the arterial pressure distends the baroreceptors that transmit afferent signals to the central nervous system, resulting in negative feedback signals to the circulation. Thus, there is an increase of the efferent vagal activity and a reduction of the sympathetic activity, reducing the arterial pressure ${ }^{30}$. Therefore, the reflex control of the circulation and ventilation requires the integration among several systems of control, which are represented in Figure $1^{22}$.

The chemoreflex sensitivity is abnormally increased in patients with $\mathrm{HF}^{31-37}$, resulting in an exaggerated increase in pulmonary ventilation ${ }^{37}$ and muscle sympathetic nervous activity $^{31}$. This exaggerated increase in chemoreflex sensitivity is associated with the reduced negative feedback system of the arterial baroreflex ${ }^{32}$. This demonstrates a impairment in the ventilation and circulation adjustment systems that contribute to the pathophysiology of the HF, since the increase in sympathetic activation ${ }^{38}$ results in an adrenergic vasoconstriction and an increase of the left and right ventricular afterload, being the sympathetic hyperactivation an important predictor of mortality in $\mathrm{HF}^{39}$. In addition, the exacerbation of the chemoreflex is related to reductions in functional capacity ${ }^{36,40}$. Therefore, patients with HF and exacerbated chemoreflex might present a greater limitation of exercise performance. 
The ventilatory responses to the exercise can be modulated by the chemoreceptors. Studies suggest that both peripheral and central chemoreflexes contribute to the occurrence of hyperventilation during exercise in HF. Indeed, patients with abnormal elevation of the ventilation/carbon dioxide production slope $\left(\dot{\mathrm{V}}_{\mathrm{E}} / \dot{\mathrm{V}}_{\mathrm{CO} 2}\right)(>34)$ present increased peripheral and central chemoreflex sensitivity $^{41}$. However, the inhibition of the peripheral chemoreflex, via dihydrocodeine, can reduce the $\dot{\mathrm{V}}_{\mathrm{E}} / \dot{\mathrm{V}}_{\mathrm{CO} 2}$ slope during progressive exercise ${ }^{42}$. Hyperventilation during exercise can also be directly mediated by skeletal metaboreflex or the central chemoreflex could be indirectly induced ${ }^{43}$, since the metaboreflex is a strong predictor of central chemoreflex activity in patients with $\mathrm{HF}^{32}$. It is important to note that both central chemoreflex and ventilatory response induced by muscle skeletal metaboreflex correlated significantly with $\dot{\mathrm{V}}_{\mathrm{E}} / \dot{\mathrm{V}}_{\mathrm{CO} 2}$ slope during progressive exercise in $\mathrm{HF}^{41}$.

Another changed ventilatory response to exercise, known as oscillatory ventilation or periodic breathing ${ }^{44,45}$, can be related to abnormal responses of chemoreflex. A study conducted in patients with HF showed that the peripheral chemoreflex sensitivity contributes in the genesis of the oscillatory ventilation at rest ${ }^{46}$, since the inhibition of the peripheral chemoreflex normalizes the ventilation in these patients. The inspiratory

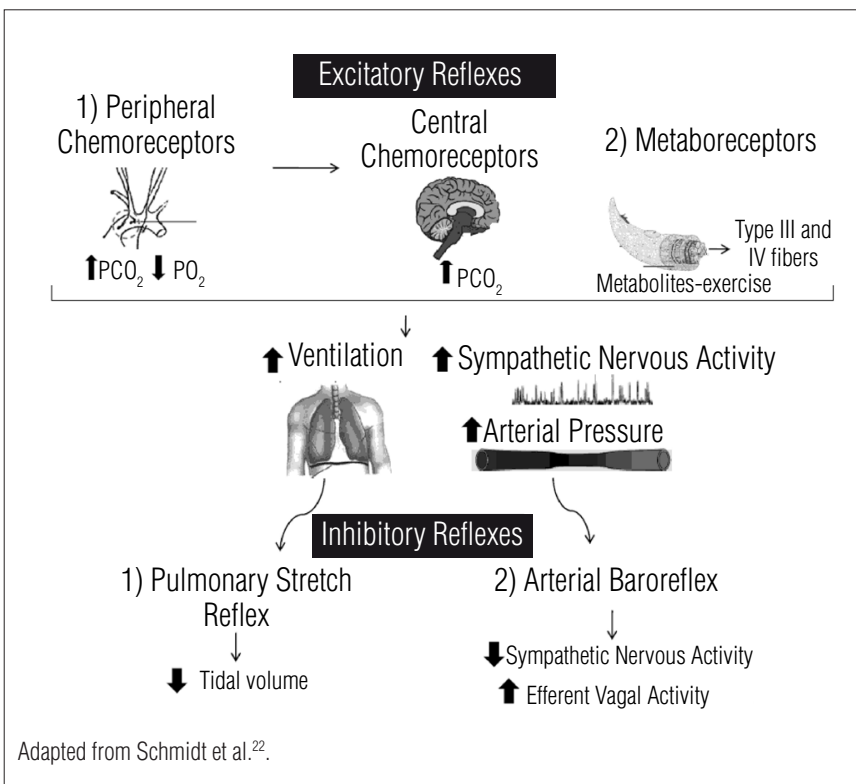

Figure 1. The adjustments of the ventilatory and circulatory responses depend on the interaction of several reflexes. The main excitatory reflexes include the central chemoreflex and the peripheral chemoreflex stimulated by changes in partial pressures of $\mathrm{CO}_{2}$ and $\mathrm{O}_{2}$, respectively, as well as the metaboreflex activated by the accumulation of metabolites during the exercise. These reflexes induce increases in the ventilation and adrenergic vasoconstriction that increases blood pressure. On the other hand, the increase of the ventilation stimulates lung stretch receptors preventing further increase in inspiratory volume, while the increase in blood pressure stimulates the baroreceptors which decrease the sympathetic nervous activity and increase the efferent vagal activity reducing blood pressure. muscular training may also attenuate the oscillatory ventilation during exercise in patients with $\mathrm{HF}$ and inspiratory muscle weakness. In fact, the inspiratory muscle training at $30 \% \mathrm{PI}_{\max }$ reduces the oscillations of ventilation at $57 \%$, concomitant to the increase of $115 \%$ of the inspiratory muscle strength ${ }^{14,47}$. Taking into consideration that oscillatory ventilation may be originated by peripheral chemoreflex, we tested the hypothesis that the chemoreflex is exacerbated in patients with HF and inspiratory muscle weakness. This study demonstrated an inverse association between the peripheral chemoreflex and $\mathrm{PI}_{\max }(\mathrm{r}=-$ $0.57, \mathrm{p}=0.01$ ), i.e., the inspiratory muscle weakness is related to the exacerbation of the peripheral chemoreflex ${ }^{24}$ as shown in Figure 2. Indeed, the group with inspiratory muscle weakness presented a greater peripheral chemoreflex compared with patients with the inspiratory muscle strength preserved ${ }^{24}$. Thus, thereductionoftheinspiratorymusclestrengthcanaggravatethe exacerbation of chemoreflex sensitivity in patients with HF, which could potentially be related to reductions in functional capacity and to exercise intolerance ${ }^{36,41}$.

\section{Inspiratory muscle metaboreflex in healthy subjects $:: \therefore$.}

The activation of the metaboreflex by the contraction of the skeletal muscles is well-known. However, only in the last decade it was described that the metaboreflex could also be activated by the respiratory muscles working ${ }^{2-7,48}$. Initially,

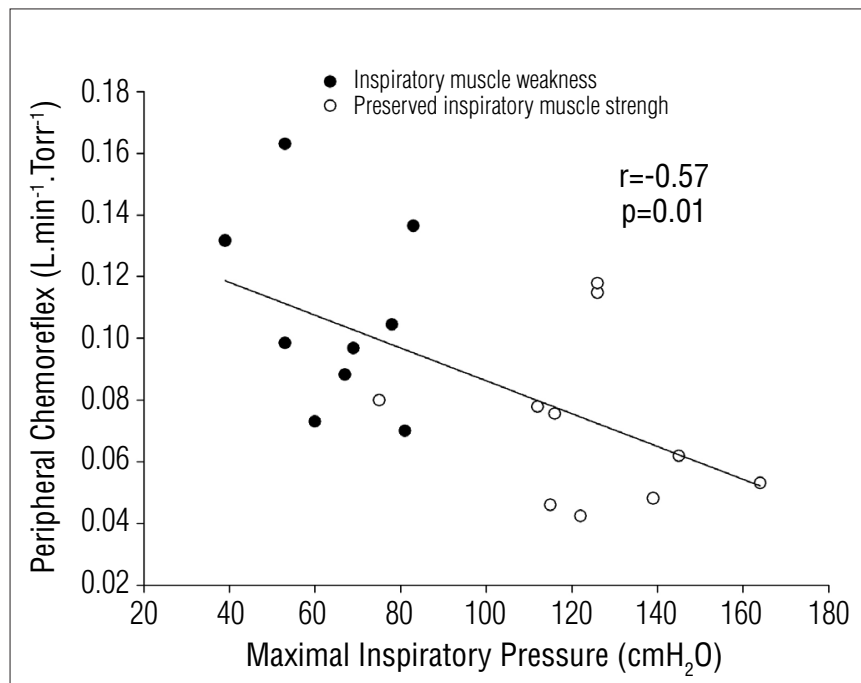

With permission Callegaro et al..$^{24}$

Figure 2. Association between maximal inspiratory pressure (expressed in absolute values) and peripheral chemoreflex in patients with heart failure. Open circles represent patients with preserved inspiratory muscle strength and closed circles represent patients with inspiratory muscle weakness. 
it was demonstrated that physical exercise (intensity $>85 \%$ of the maximal oxygen consumption $\left[\mathrm{V}_{2}{ }_{\text {maxx }}\right]$ induces diaphragmatic muscle fatigue ${ }^{49}$ even in elite athletes ${ }^{50}$. Then, it was observed that the increase in the inspiratory muscle work (via inspiratory resistance) increases the levels of noradrenaline reducing the blood flow in the leg during maximal exercise on a bicycle ${ }^{48}$. These findings led to the hypothesis of the existence of an "inspiratory metaboreflex" activated during physical exercise. A theory confirmed in a subsequent study verified the existence of redistribution of blood flow of the active peripheral muscles to the diaphragm, corresponding to more than $14-16 \%$ of cardiac output ${ }^{5}$. Moreover, in an experimental protocol of induction of the inspiratory metaboreflex, through the intense inspiratory effort (inspiratory resistance $=60 \%$ of $\mathrm{PI}_{\max }$ ) and sustained (ratio between inspiratory time and the total duration of the respiratory cycle $[\mathrm{TI} / \mathrm{TTot}]=0.70$ ), showed that inspiratory muscle fatigue increases muscle sympathetic nerve activity ${ }^{2}$ and reduces the muscle blood flow for the inactive leg ${ }^{3,4}$ due to the adrenergic vasoconstriction. This response seems to be mediated by the metabolic stimulation of small afferent fibers types III and IV from the respiratory muscles, especially from the diaphragm ${ }^{51}$. The effects of redistribution of the blood flow during the fatiguing inspiratory work showed the existence of an inspiratory metaboreflex, represented in Figure $3^{52}$. Thus, the activation of the inspiratory metaboreflex during physical exercise that induces inspiratory muscle fatigue ${ }^{49}$ may limit physical performance ${ }^{12,53}$ due to the reduction of blood flow to the active skeletal muscles ${ }^{48}$, exacerbating the fatigue of the peripheral muscles ${ }^{8}$. On the other hand the reduction of inspiratory muscle work through mechanical ventilation in healthy subjects increases the exercise duration in $14 \%^{6}$ and attenuates quadriceps fatigue during exercise ${ }^{8}$, probably because it inhibits the inspiratory metaboreflex. Moreover, the conditioning of the inspiratory muscles could minimize the effects of the activation of the inspiratory metaboreflex. Studies show that inspiratory muscle training, performed at $50 \%$ of $\mathrm{PI}_{\text {max }}$, attenuates the pressure response ${ }^{54}$ and reduces the fatigue of the plantar flexors muscles during the activation of the inspiratory metaboreflex in healthy subjects 9 . These effects of inspiratory muscle training could contribute to improve the exercise performance. In fact, inspiratory muscle training prolongs the duration of the exercise in bicycle, and also reduces the lactate concentration at the end of progressive exercise test in active subjects ${ }^{55}$. Additionally, regular aerobic training also attenuates inspiratory metaboreflex. A recent study showed that the inspiratory metaboreflex is attenuated in trained subjects when compared with sedentary healthy subjects ${ }^{56}$. In fact, fatiguing inspiratory muscle work induced peripheral vasoconstriction with reduced blood

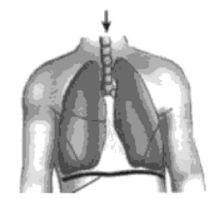

Resistive inspiration

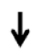
$\uparrow$ metabolites
Inspiratory fatigue

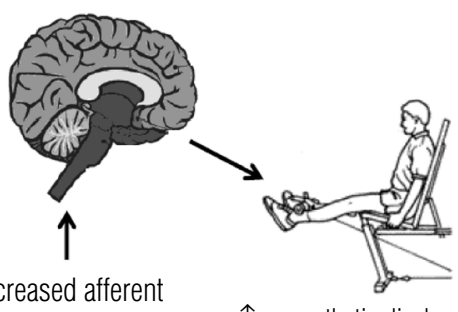

$\uparrow$ sympathetic discharge $\uparrow$ vasoconstriction $\uparrow$ fatigue of the active peripheral muscles $\downarrow 0_{2}$ transport

Adapted from Dempsey et al. 52

Figure 3. Illustration of the inspiratory metaboreflex activated during the fatiguing inspiratory muscle work due to metabolite accumulation that increase afferent phrenic discharge resulting in the increase of the sympathetic activity and peripheral vasoconstriction, exacerbating the fatigue of the active peripheral muscles.

flow in the calf of sedentary subjects, but remain almost unchanged in aerobically trained subjects (Figure 4$)^{56}$. This effect of aerobic training on the inspiratory metaboreflex is probably related to the increased oxidative capacity ${ }^{57}$, the strength of inspiratory muscles ${ }^{58}$ and of the fatigue resistance of the diaphragm ${ }^{59}$. Alternatively, the administration of transcutaneous electric nervous stimulation (TENS) in the cervicothoracic region attenuates the muscle skeletal metaboreflex, probably due to the blockage of the sympathetic nervous activity in young and old subjects, as recently demostrated $^{60}$. Thus, the application of TENS in the cervicothoracic region could possibly attenuate the inspiratory metaboreflex impact on physical performance, but this hypothesis still need to be further investigated.

\section{Inspiratory muscle metaboreflex in subjects with heart failure $: \because$.}

The inspiratory metaboreflex may limit the exercise performance mainly in HF patients with inspiratory muscle weakness ${ }^{15}$. In fact, the weakness of inspiratory muscle often observed in patients with $\mathrm{HF}^{16,61-63}$ may be related to exercise intolerance. In addition, the reduction in inspiratory muscle oxygenation mediated by acute physical exercise in patients with $\mathrm{HF}^{64}$ could increase the ventilatory work and exacerbate the inspiratory muscle metaboreflex limiting the exercise tolerance due to the reduction of the perfusion of the locomotor muscles, as have been previously mentioned. 
Thus, strategies that reduce the inspiratory muscle work and attenuate the inspiratory metaboreflex could improve the exercise tolerance. In fact, the reduction of inspiratory muscle work through noninvasive ventilation in the proportional assisted ventilation may improve physical performance in patients with HF. Recently, it has been shown that such intervention improves the oxygenation of the peripheral muscle microcirculation, which may be compatible with the improvement of local blood flow ${ }^{65}$. These findings have been currently confirmed by Olson et al. ${ }^{66}$, whom found that the reduction in inspiratory muscle work increased the leg blood flow and the cardiac output only in patients with HF, remaining unchanged in healthy controls subjects. It means that patients with $\mathrm{HF}$ are more susceptible to exercise intolerance due to the effects of the metaboreflex activation by the inspiratory muscles work, so that the inspiratory muscle training attenuates the inspiratory metaboreflex in patients with HF and with the inspiratory muscles weakness (Figure 5$)^{15}$. These effects of inspiratory muscle training may contribute to the improvement of the cardiorespiratory responses, functional capacity and tolerance to the exercise in patients with $\mathrm{HF}^{14}$. A recent study confirmed the findings of improvement in the exercise tolerance after inspiratory muscle training ${ }^{67}$, being the improvement on functional capacity occurs even in HF patients with left ventricle assist device ${ }^{68}$. Therefore, the conditioning of inspiratory muscles via inspiratory muscle training could attenuate the inspiratory metaboreflex with possible benefits for the improvement of the exercise tolerance in patients with HF. Thus, interventions that attenuate the activation of the inspiratory metaboreflex may be beneficial for patients that present exercise intolerance, including those with chronic obstructive pulmonary disease. In animal models of HF, it has also been demostrate that inspiratory muscle training improves hemodynamic function, respiratory mechanics and cardiovascular autonomic control ${ }^{69}$.

Some studies suggest that noninvasive ventilation could temporarily attenuate the activation of the inspiratory metaboreflex due to the reduction of the inspiratory muscle work in patients with chronic obstructive pulmonary disease. In the study of Borghi-Silva et al. ${ }^{70}$, the bi-level positive airway pressure ventilation improved the $\mathrm{O}_{2}$ peripheral saturation and reduced quadriceps muscle fatigue during the isokinetic exercise. These data had been supported by a study that demonstrated that the reduction of the inspiratory muscle work, via inhalation of mixture containing helium at $79 \%$, counterbalanced with oxygen, improved the exercise tolerance in patients with chronic obstructive pulmonary disease that performed an exercise protocol with constant load and high intensity ${ }^{71}$. Furthermore, the use of positive pressure support increases the resistance

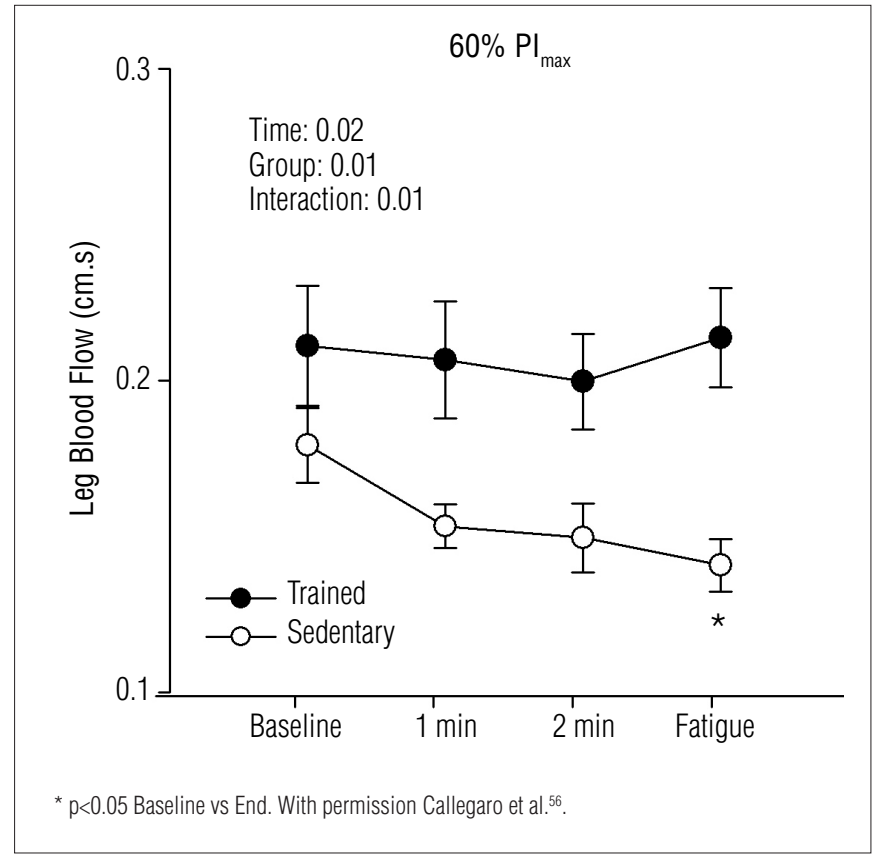

Figure 4. Leg blood flow response, assessed by Doppler ultrasonography, during the induction of the inspiratory metaboreflex at $60 \% \mathrm{PI}_{\max }$. Endurance trained subjects are represented by close circles and sedentary subjects are represented by open circles.

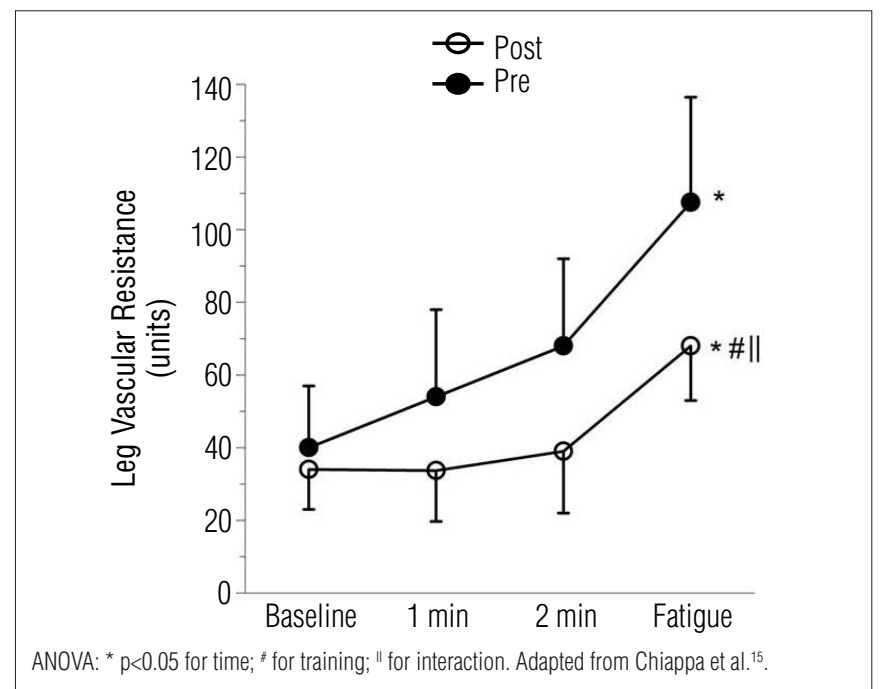

Figure 5. Leg vascular resistance measured via venous occlusion plethysmography during the induction of the inspiratory metaboreflex at $60 \%$ $\mathrm{PI}_{\max }$ pre and post one month of inspiratory muscle training. The values of the leg vascular resistance pre inspiratory muscle training are represented by close circles. The values of the leg vascular resistance post inspiratory muscle training are represented by open circles.

to exercise in these patients ${ }^{72}$. Thus, non-invasive ventilatory support could help maintain the physical training of patients that present severe exercise limitations related to chronic obstructive pulmonary disease, probably due to attenuation of the inspiratory metaboreflex ${ }^{73}$. 


\section{Implications for the physical therapist practice : : :}

The inspiratory muscle training improves functional capacity and quality of life in patients with HF and inspiratory muscle weakness ${ }^{14}$. These findings were confirmed in a recent study that investigated the effects of inspiratory muscle training in $\mathrm{HF}$ and found, in their sample, a vast majority of patients with inspiratory muscle weakness ${ }^{67}$.

In addition, the association of inspiratory muscle training with aerobic training promotes additional effects on $\mathrm{VO}_{2 \text { peak }}$ in patients with inspiratory muscle weakness ${ }^{58}$. Randomized controlled clinical trials with a representative sample size could investigate isolated effects ${ }^{74}$, and compared effects between aerobic training and inspiratory muscle training in patients with inspiratory muscle weakness.

Therefore, it is recommended that the physical therapist routinely evaluate inspiratory muscle strength in patients with HF in order to identify patients with muscle weakness, which could benefit from inspiratory muscular training.

\section{Conclusion $: \because:$}

Patients with HF may present changes in inspiratory muscle function associated with chemoreflex and inspiratory metaboreflex hyperactivity, which can exacerbate the exercise intolerance.

\section{References: ::}

1. Clark AL, Poole-Wilson PA, Coats AJ. Exercise limitation in chronic heart failure: central role of the periphery. J Am Coll Cardiol. 1996;28(5):1092-102.

2. St Croix CM, Morgan BJ, Wetter TJ, Dempsey JA. Fatiguing inspiratory muscle work causes reflex sympathetic activation in humans. J Physiol. 2000;529(Pt 2):493-504.

3. Sheel AW, Derchak PA, Morgan BJ, Pegelow DF, Jacques AJ, Dempsey JA. Fatiguing inspiratory muscle work causes reflex reduction in resting leg blood flow in humans. J Physiol. 2001;537(Pt 1):277-89

4. Sheel AW, Derchak PA, Pegelow DF, Dempsey JA. Threshold effects of respiratory muscle work on limb vascular resistance. Am J Physiol Heart Circ Physiol. 2002;282(5):H1732-8.

5. Harms CA, Wetter TJ, McClaran SR, Pegelow DF, Nickele GA, Nelson WB, et al. Effects of respiratory muscle work on cardiac output and its distribution during maximal exercise. J Appl Physiol. 1998;85(2):609-18

6. Harms CA, Wetter TJ, St Croix CM, Pegelow DF, Dempsey JA. Effects of respiratory muscle work on exercise performance. J Appl Physiol. 2000;89(1):131-8.

7. Derchak PA, Sheel AW, Morgan BJ, Dempsey JA. Effects of expiratory muscle work on muscle sympathetic nerve activity. J Appl Physiol. 2002;92(4):1539-52.

8. Romer LM, Lovering AT, Haverkamp HC, Pegelow DF, Dempsey JA. Effect of inspiratory muscle work on peripheral fatigue of locomotor muscles in healthy humans. J Physiol. 2006;571(Pt 2):425-39.

9. McConnell AK, Lomax M. The influence of inspiratory muscle work history and specific inspiratory muscle training upon human limb muscle fatigue. J Physiol. 2006;577(Pt 1):445-57.

10. Dempsey JA, Sheel AW, St Croix CM, Morgan BJ. Respiratory influences on sympathetic vasomotor outflow in humans. Respir Physiol Neurobiol. 2002;130(1):3-20.

11. Harms CA. Insights into the role of the respiratory muscle metaboreflex. J Physiol. 2007:584(Pt 3):711.

12. Dempsey JA, McKenzie DC, Haverkamp HC, Eldridge MW. Update in the understanding of respiratory limitations to exercise performance in fit, active adults. Chest. 2008;134(3):613-22.

13. Romer LM, Polkey MI. Exercise-induced respiratory muscle fatigue: implications for performance. J Appl Physiol. 2008;104(3):879-88.

14. Dall'Ago P, Chiappa GR, Guths H, Stein R, Ribeiro JP. Inspiratory muscle training in patients with heart failure and inspiratory muscle weakness: a randomized trial. J Am Coll Cardiol. 2006;47(4):757-63

15. Chiappa GR, Roseguini BT, Vieira PJ, Alves CN, Tavares A, Winkelmann ER, et al. Inspiratory muscle training improves blood flow to resting and exercising limbs in patients with chronic heart failure. J Am Coll Cardiol. 2008;51(17):1663-71.

16. Ribeiro JP, Chiappa GR, Neder JA, Frankenstein L. Respiratory muscle function and exercise intolerance in heart failure. Curr Heart Fail Rep. 2009;6(2):95-101.
17. Greutmann M, Le TL, Tobler D, Biaggi P, Oechslin EN, Silversides CK, et al. Generalised muscle weakness in young adults with congenital heart disease. Heart. 2011;97(14):1164-8.

18. Neves LM, Karsten M, Neves VR, Beltrame T, Borghi-Silva A, Catai AM. Relationship between inspiratory muscle capacity and peak exercise tolerance in patients post-myocardial infarction. Heart Lung. 2012;41(2):137-45

19. Filusch A, Ewert R, Altesellmeier M, Zugck C, Hetzer R, Borst MM, et al. Respiratory muscle dysfunction in congestive heart failure--the role of pulmonary hypertension. Int $\mathrm{J}$ Cardiol. 2011;150(2):182-5

20. Meyer FJ, Borst MM, Zugck C, Kirschke A, Schellberg D, Kübler W, et al. Respiratory muscle dysfunction in congestive heart failure: clinical correlation and prognostic significance. Circulation. 2001;103(17):2153-8.

21. Frankenstein L, Nelles M, Meyer FJ, Sigg C, Schellberg D, Remppis BA, et al. Validity, prognostic value and optimal cutoff of respiratory muscle strength in patients with chronic heart failure changes with beta-blocker treatment. Eur J Cardiovasc Prev Rehabil. 2009;16(4):424-9.

22. Schmidt H, Francis DP, Rauchhaus M, Werdan K, Piepoli MF. Chemo- and ergoreflexes in health, disease and ageing. Int J Cardiol. 2005;98(3):369-78.

23. Tumminello G, Guazzi M, Lancellotti P, Piérard LA. Exercise ventilation inefficiency in hear failure: pathophysiological and clinical significance. Eur Heart J. 2007;28(6):673-8

24. Callegaro CC, Martinez D, Ribeiro PA, Brod M, Ribeiro JP. Augmented peripheral chemoreflex in patients with heart failure and inspiratory muscle weakness. Respir Physiol Neurobiol. 2010;171(1):31-5

25. Guimarães GV, Belli JFC, Bacal F, Bocchi EA. Behavior of central and peripheral chemoreflexes in heart failure. Arq Bras Cardiol. 2011;96(2):161-7.

26. Somers VK, Mark AL, Zavala DC, Abboud FM. Influence of ventilation and hypocapnia on sympathetic nerve responses to hypoxia in normal humans. J Appl Physiol. 1989;67(5):2095-100.

27. Somers VK, Mark AL, Zavala DC, Abboud FM. Contrasting effects of hypoxia and hypercapnia on ventilation and sympathetic activity in humans. J Appl Physiol. 1989;67(5):2101-6.

28. Marshall JM. Peripheral chemoreceptors and cardiovascular regulation. Physiol Rev. 1994;74(3):543-94

29. Guyton AC, Hall JE. Tratado de fisiologia médica. $11^{\text {a }}$ Ed. Rio de Janeiro: Editora Elsevier; 2006.

30. Callegaro CC, Taylor JA. Age-related effects of vagotonic atropine on cardiovagal baroreflex gain Neurobiol Aging. 2012;33(2):368-74

31. Di Vanna A, Braga AM, Laterza MC, Ueno LM, Rondon MU, Barretto AC, et al. Blunted muscle vasodilatation during chemoreceptor stimulation in patients with heart failure. Am J Physio Heart Circ Physiol. 2007;293(1):H846-52. 
32. Ponikowski PP, Chua TP, Francis DP, Capucci A, Coats AJ, Piepoli MF. Muscle ergoreceptor overactivity reflects deterioration in clinical status and cardiorespiratory reflex control in chronic heart failure. Circulation. 2001;104(19):2324-30

33. Chua TP, Clark AL, Amadi AA, Coats AJ. Relation between chemosensitivity and the ventilatory response to exercise in chronic heart failure. J Am Coll Cardiol. 1996;27(3):650-7.

34. Sun SY, Wang W, Zucker IH, Schultz HD. Enhanced peripheral chemoreflex function in conscious rabbits with pacing-induced heart failure. J Appl Physiol. 1999;86(4):1264-72.

35. Chua TP, Ponikowski PP, Harrington D, Chambers J, Coats AJ. Contribution of peripheral chemoreceptors to ventilation and the effects of their suppression on exercise tolerance in chronic heart failure. Heart. 1996;76(6):483-9.

36. Chua TP, Ponikowski P, Webb-Peploe K, Harrington D, Anker SD, Piepoli M, et al. Clinical characteristics of chronic heart failure patients with an augmented peripheral chemoreflex. Eur Heart J. 1997;18(3):480-6.

37. Narkiewicz K, Pesek CA, van de Borne PJ, Kato M, Somers VK. Enhanced sympathetic and ventilatory responses to central chemoreflex activation in heart failure. Circulation. 1999;100(3):262-7

38. Ciarka A, Najem B, Cuylits N, Leeman M, Xhaet O, Narkiewicz K, et al. Effects of peripheral chemoreceptors deactivation on sympathetic activity in heart transplant recipients. Hypertension. 2005;45(5):894-900

39. Munhoz RT, Negrão CE, Barretto AC, Ochiai ME, Cardoso JN, Morgado PC, et al. Microneurography and venous occlusion plethysmography in heart failure: correlation with prognosis. Arq Bras Cardiol. 2009;92(1):46-53.

40. Ponikowski P, Chua TP, Anker SD, Francis DP, Doehner W, Banasiak W, et al. Peripheral chemoreceptor hypersensitivity: an ominous sign in patients with chronic heart failure. Circulation. 2001;104(5):544-9.

41. Ponikowski P, Francis DP, Piepoli MF, Davies LC, Chua TP, Davos CH, et al. Enhanced ventilatory response to exercise in patients with chronic heart failure and preserved exercise tolerance: marker of abnormal cardiorespiratory reflex control and predictor of poor prognosis. Circulation. 2001;103(7):967-72.

42. Chua TP, Harrington D, Ponikowski P, Webb-Peploe K, Poole-Wilson PA, Coats AJ. Effects of dihydrocodeine on chemosensitivity and exercise tolerance in patients with chronic heart failure. J Am Coll Cardiol. 1997:29(1):147-52

43. Piepoli MF, Ponikowski PP, Volterrani M, Francis D, Coats AJ. Aetiology and pathophysiological implications of oscillatory ventilation at rest and during exercise in chronic heart failure. Do Cheyne and Stokes have an important message for modern-day patients with heart failure? Eur Heart J. 1999;20(13):946-53.

44. Ribeiro JP, Knutzen A, Rocco MB, Hartley H, Colucci WS. Periodic Breathing during exercise in severe heart failure. Reversal with milrinone or cardiac transplantation. Chest. 1987;92(3):555-6.

45. Ribeiro JP, Stein R, Chiappa GR. Beyond peak oxygen uptake: new prognostic markers from gas exchange exercise tests in chronic heart failure. J Cardiopulm Rehabil. 2006;26(2):63-71.

46. Ponikowski P, Anker SD, Chua TP, Francis D, Banasiak W, Poole-Wilson PA, et al. Oscillatory breathing patterns during wakefulness in patients with chronic heart failure: clinical implications and role of augmented peripheral chemosensitivity. Circulation. 1999;100(24):2418-24.

47. Stein R, Chiappa GR, Güths H, Dall'Ago P, Ribeiro JP. Inspiratory muscle training improves oxygen uptake efficiency slope in patients with chronic heart failure. J Cardiopulm Rehabil Prev. 2009;29(6):392-5

48. Harms CA, Babcock MA, McClaran SR, Pegelow DF, Nickele GA, Nelson WB, et al. Respiratory muscle work compromises leg blood flow during maximal exercise. J Appl Physiol. 1997;82(5):1573-83.

49. Johnson BD, Babcock MA, Suman OE, Dempsey JA. Exercise-induced diaphragmatic fatigue in healthy humans. J Physiol. 1993;460:385-405.

50. Babcock MA, Pegelow DF, Johnson BD, Dempsey JA. Aerobic fitness effects on exercise-induced low-frequency diaphragm fatigue. J Appl Physiol. 1996;81(5):2156-64.

51. Hill JM. Discharge of group IV phrenic afferent fibers increases during diaphragmatic fatigue. Brain Res. 2000;856(1-2):240-4.

52. Dempsey JA, Romer L, Rodman J, Miller J, Smith C. Consequences of exercise-induced respiratory muscle work. Respir Physiol Neurobiol. 2006;151(2-3):242-50.
53. Dempsey JA, Amann M, Romer LM, Miller JD. Respiratory system determinants of peripheral fatigue and endurance performance. Med Sci Sports Exerc. 2008;40(3):457-61.

54. Witt JD, Guenette JA, Rupert JL, McKenzie DC, Sheel AW. Inspiratory muscle training attenuates the human respiratory muscle metaboreflex. J Physiol. 2007;584(Pt 3):1019-28.

55. Spengler CM, Roos M, Laube SM, Boutellier SML. Decreased exercise blood lactate concentrations after respiratory endurance training in humans. Eur $\mathrm{J}$ Appl Physiol. 1999;79(4):299-305

56. Callegaro CC, Ribeiro JP, Tan C0, Taylor JA. Attenuated inspiratory muscle metaboreflex in endurance-trained individuals. Respir Physiol Neurobiol. 2011;177(1):24-9.

57. Powers SK, Criswell D, Lieu FK, Dodd S, Silverman H. Exercise-induced cellular alterations in the diaphragm. Am J Physiol. 1992;263(5 Pt 2):R1093-8.

58. Winkelmann ER, Chiappa GR, Lima COC, Viecili PRN, Stein R, Ribeiro JP. Addition of inspiratory muscle training to aerobic training improves cardiorespiratory responses to exercise in patients with heart failure and inspiratory muscle weakness. Am Heart J. 2009;158(5):768.e1-7.

59. Vrabas IS, Dodd SL, Powers SK, Hughes M, Coombes J, Fletcher L, et al. Endurance training reduces the rate of diaphragm fatigue in vitro. Med Sci Sports Exerc. 1999;31(11):1605-12.

60. Vieira PJC, Ribeiro JP, Cipriano CJr, Umpierre D, Cahalin LP, Moraes RS, et al. Effect of transcutaneous electrical nerve stimulation on muscle metaboreflex in healthy young and older subjects. Eur J Appl Physiol. 2012;112(4):1327-34.

61. Hammond MD, Bauer KA, Sharp JT, Rocha RD. Respiratory muscle strength in congestive heart failure. Chest. 1990;98(5):1091-4

62. Witt C, Borges AC, Haake H, Reindl I, Kleber FX, Baumann G. Respiratory muscle weakness and normal ventilatory drive in dilative cardiomyopathy. Eur Heart J. 1997;18:1322-8.

63. Walsh JT, Andrews R, Johnson P, Phillips L, Cowley AJ, Kinnear WJ. Inspiratory muscle endurance in patients with chronic heart failure. Heart. 1996;76(4):332-6.

64. Mancini DM, Ferraro N, Nazzaro D, Chance B, Wilson JR. Respiratory muscle deoxygenation during exercise in patients with heart failure demonstrated with near-infrared spectroscopy. J Am Coll Cardiol. 1991;18(2):492-8

65. Borghi-Silva A, Carrascosa C, Oliveira CC, Barroco AC, Berton DC, Vilaça D, et al Effects of respiratory muscle unloading on leg muscle oxygenation and blood volume during high-intensity exercise in chronic heart failure. Am J Physiol Heart Circ Physiol. 2008;294(6):H2465-72.

66. Olson TP, Joyner MJ, Dietz NM, Eisenach JH, Curry TB, Johnson BD. Effects of respiratory muscle work on blood flow distribution during exercise in heart failure. J Physiol. 2010;588(P 13):2487-501.

67. Bosnak-Guclu M, Arikan H, Savci S, Inal-Ince D, Tulumen E, Aytemir K, et al. Effects of inspiratory muscle training in patients with heart failure. Respir Med. 2011;105(4):1671-81

68. Laoutaris ID, Dritsas A, Brown MD, Manginas A, Kallistratos MS, Sfirakis $P$, et al Inspiratory muscle training in a patient with left ventricular assist device. Hellenic J Cardiol. 2006;47(4):238-41.

69. Jaenisch RB, Hentschke VS, Quagliotto E, Cavinato PR, Schmeing LA, Xavier LL, et al. Respiratory muscle training improves hemodynamics, autonomic function, baroreceptor sensitivity, and respiratory mechanics in rats with heart failure. J Appl Physiol. 2011;111(6):1664-70.

70. Borghi-Silva A, Di Thommazo L, Pantoni CB, Mendes RG, Salvini Tde F, Costa D. Non-invasive ventilation improves peripheral oxygen saturation and reduces fatigability of quadriceps in patients with COPD. Respirology. 2009;14(4):537-44.

71. Chiappa GR, Queiroga FJr, Meda E, Ferreira LF, Diefenthaeler F, Nunes M, et al. Heliox improves oxygen delivery and utilization during dynamic exercise in patients with chronic obstructive pulmonary disease. Am J Respir Crit Care Med. 2009;179(11):1004-10.

72. van't Hul A, Gosselink R, Hollander P, Postmus P, Kwakkel G. Acute effects of inspiratory pressure support during exercise in patients with COPD. Eur Respir J. 2004;23(1):34-40.

73. Borghi-Silva A, Mendes RG, Toledo AC, Malosá Sampaio LM, da Silva TP, Kunikushita LN, et al. Adjuncts to physical training of patients with severe COPD: oxygen or noninvasive ventilation? Respir Care. 2010;55(7):885-94.

74. Wong E, Selig S, Hare DL. Respiratory muscle dysfunction and training in chronic heart failure Heart Lung Circ. 2011;20(5):289-94 